\title{
ASPECTOS TÉCNICOS DE LA INDUSTRIA DEL CANNABIS \\ (APROXIMACIONES A LA PLANTA)
}

\author{
JoRGE RUBIO EsCALONA* \\ MediPharm Labs \\ México, Nabbis.com \\ jrpublicaffairs@outlook.com
}

https://doi.org/10.36105/iut.2021n33.12

El cannabis pertenece a la familia de las plantas cannabáceas, es un amplio término que se puede usar para describir productos orgánicos (cannabinoides), derivados de las tres variedades de planta: sativa, indica e híbridas. En México el término común que damos al cannabis es el de marihuana y contiene altos porcentajes de Tetrahidrocannabinol (THC). El Hemp o cáñamo es la variedad no psicoactiva del cannabis que ha tenido un uso industrial desde hace cientos de años, hasta la más reciente legalización en EUA, el Farm Bill Act, que legalizó la industrialización de esta planta en el año 2018.

Los derivados, resinas y flores secas existen en varias presentaciones y se utilizan para diversos mercados como son: el industrial, el medicinal y el recreativo.

El cannabis es una planta dioica, lo que significa que hay machos y hembras. La polinización de estas plantas se hace a través del viento y si crece a la

* Emprendedor de la industria de cannabis desde 2017 en Vancouver, Canadá. Cofundador de la plataforma Nabbis. Es socio y ha trabajado para desarrollo de negocios y estrategias de mercado en: Clarity Cannabis, Emerald Health Therapeutics, Cannaviri Group, Baked Edibles, American Hemp Ventures y Endosmart. En su experiencia profesional en México trabajó en las áreas de market access y desarrollo de negocio en la industria farmacéutica, dispositivos médicos y fue funcionario del Gobierno Federal. Es miembro del Partido Liberal Canadiense. Ha sido conferencista sobre regulación de cannabis en Lift\&Co Expo Vancouver, CBD. io Las Vegas y CBD Vox en Reino Unido. Participa regularmente en el Podcast Cannabis Update de Calgary, The Ganjha Show en la India y The Joint Venture en Boston. Ha colaborado en entrevistas y artículos en: The Globe and Mail, el Sol de México, Lattin Canada, Weed Lovers, Benzinga, The Cannavist. Estudió la carrera en administración de empresas y cuenta con tres estudios de posgrado en Negocios, Gestión Pública, Análisis Político y Medios en México en el Tecnológico de Monterrey y Victoria University. 
intemperie se hace difícil su control ya que requiere de nutrientes, luz, agua y humedad. De igual manera se contamina fácilmente por plagas, pesticidas, así como materiales contaminantes que existen en el medio ambiente. Es una planta anual que tarda en crecer de 3 a 6 meses en su hábitat óptimo.

Se piensa que en México puede tener más de dos ciclos al año y se ha sembrado principalmente en los estados de la Costa del Pacifico, desde Sonora hasta Oaxaca. Uno de los aspectos más importantes a tomar en cuenta en la siembra y extracción de productos de cannabis es el llamado testing que implica las siguientes pruebas: potencia de cannabinoides, perfil de terpenos, micotoxinas, humedad, pesticidas y metales pesados.

Los compuestos químicos denominados cannabinoides son exclusivos de esta planta y están presentes en la resina que secretan los tricomas, que son producidos en altas concentraciones por las plantas de sexo femenino principalmente.

Las hojas y capullos floreados de las plantas del cannabis contienen más de 400 diferentes compuestos distribuidos entre diversas clases y se han logrado identificar más de 120 cannabinoides en la planta. Otros compuestos relevantes son: terpenos, flavonoides y compuestos vegetales. El resto de la planta incluye grasas, ceras y clorofila.

La variedad sativa tiene más potencial psicoactivo y sus efectos tienen un denominado upper effect, es decir, que van hacia la "cabeza", al contrario de la indica que tiene más efecto terapéutico hacia el "cuerpo", "sleepy effect". Los capullos del cannabis sativa son largos, los de indica son más compactos y densos.

Existen miles de cepas de plantas híbridas, que son mezcla de las variedades sativa e indica, y la manera más adecuada de clasificarlas es: sativas dominantes o indicas dominantes. En los mercados recreativos estas mezclas provienen de las cruzas que llevan a cabo los criadores con razas autóctonas como: Kush, OG, Haze, Golden, Afghani, Cookies entre muchas otras. En los años 70s los contenidos de THC rodaban los $12 \%$ a $15 \%$. Ahora en los mercados legales e ilegales se pueden encontrar cepas o strains hasta con 35\% de THC en flor seca.

Los primeros registros del uso de cannabis como medicamento aparecen en China 2500 a.C. en donde se utilizaba para enfermedades como gota, fatiga, malaria y reumatismo. En la Grecia antigua el médico galeno describió su efecto "euforizante". En muchas regiones del planeta como Persia, Egipto, Jerusalén, Escocia y Nepal hay evidencia de su uso, pero fue hasta 1830 en Irlanda lugar donde Dr. O'Shaughnessy llevó a cabo los primeros experimentos de cannabis con humanos para tétanos, cólera y convulsiones.

A pesar de que hay un gran número de cannabinoides en la planta, los que tienen más estudios son el delta-9-tetrahidrocannabinol $(\Delta 9-\mathrm{THC})$ y el cannabidiol (CBD). Estos compuestos son los que dan a la planta sus propiedades recreativas o medicinales.

\section{CANNABINOIDES THC Y CBD; TETRAHIDROCANNABINOL (THC)}

Es un cannabinoide que ha causado interés recientemente debido a que es el responsable de varios efectos terapéuticos y eufóricos durante el consumo del 
cannabis. THCA (ácido tetrahydrocannabinol) es el precursor biosintético del $\mathrm{THC}$, sin embargo, tiene propiedades totalmente diferentes. La reacción química del THC se lleva a cabo cuando un capullo de cannabis (bud) es expuesto al calor durante la combustión. Calentarlo a $80-100^{\circ} \mathrm{C}$ es suficiente para causar una descarboxilación al $\Delta 9$-THC.

El THC interactúa con el sistema endocannabinoide del cuerpo. Los receptores del cannabinoide CB1, están situados a través del cuerpo, pero la concentración más alta está en el cerebro. Se cree que es el lugar donde se producen la mayor cantidad de efectos del cannabis. La alta concentración de los receptores CB1 es responsable de los efectos farmacológicos del cannabis medicinal que incluyen el placer, el aprendizaje, la memoria, el apetito, la regulación del sueño $\mathrm{y}$ la sensación del dolor.

Es fundamental llevar a cabo estudios e investigación clínica para determinar cómo puede afectar el sistema nervioso central y periférico.

\section{CANNABIDIOL (CBD)}

Inicialmente fue aislado en los años 40 siendo su estructura es similar a la del THC; pero al contrario del THC, el CBD no causa euforia. Estudios clínicos en animales han demostrado que este compuesto es efectivo como antiinflamatorio, antiansiolítico, como neuroprotector y antioxidante. Su mayor interacción se hace en los receptores $\mathrm{CB} 2$ que se distribuyen en varios órganos de nuestro cuerpo. Existen algunas condiciones donde se cree que la terapia con $\mathrm{CBD}$ puede ser efectiva como:

- Esclerosis múltiple

- Enfermedad de Parkinson

- Acné

- Psoriasis

- Depresión

- Epilepsia

- Enfermedades bacterianas

- Neuropatía Diabética

- Enfermedad de Lyme

- Déficit de atención y de hiperactividad

- Artritis reumatoide

- Esclerosis lateral

- Náusea

- Ansiedad

- Síndrome de intestino irritable

El CBD y el THC también incrementan la anandamida que juega un papel muy importante en la generación de motivación y placer. El CBD puede venir de dos fuentes: 
La primera es del cannabis que llamaremos marihuana y la segunda del cáñamo (Hemp) que es una variable del cannabis, pero con un porcentaje menor al $1 \%$ de THC.

La forma más segura de consumir estas sustancias es mediante aceites (tinturas), ya sea a manera de tópicos o en cápsulas. Si se consumen concentrados o comestibles se recomienda saber el origen y la cantidad de CBD en miligramos. Los métodos más comunes de extracción de aceite de CBD/THC son:

- A través de dióxido de carbono $\left(\mathrm{CO}_{2}\right)$.

- Etanol.

- A través de gas butano o propano.

- A través de extracciones "caseras" con aceite de coco, oliva o girasol e incluso se puede llevar a cabo con mantequilla y miel de abeja.

Otro elemento importante para considerar es el proceso de producción del CBD, que puede ser: "aislado" (isolated) o de espectro completo (full espectrum). La diferencia entre ambos es que el full espectrum es un proceso por el cual se obtuvo CBD con otros cannabinoides y el isolated solo contiene CBD que en algunas etiquetas aparece como: "CBD puro" y que utilizó un método llamado cromatografía. Los expertos señalan que el CBD full spectrum es mucho más eficiente para diversas terapias.

La planta crea terpenos que son aromas y sabores. En ambientes controlados como invernaderos, los terpenos pueden incrementarse si la planta sufre estrés, ya sea por el nivel de humedad o temperatura, incluso hacer algunos cortes pequeños a la planta puede aumentar su capacidad generar más de terpenos. Los terpenos más comunes son:

$$
\begin{array}{ll}
- & \text { Mirceno } \\
- & \text { Cariofileno } \\
- & \text { Linalool } \\
- & \text { Pineno } \\
- & \text { Limoneno } \\
- & \text { Humuleno }
\end{array}
$$

Las cepas del cannabis pueden variar significativamente en su concentración de cannabinoides y terpenos de acuerdo con la genética, las condiciones de crecimiento, cosecha, proceso de extracción de aceite, época de año y su almacenamiento. Si bien las condiciones del medio ambiente de México son mejores que en EUA o Canadá, esto no quiere decir que el cannabis mexicano pueda tener más potencia y calidad en comparación de la que se siembra en espacios cerrados o invernadero (indoor o greenhouse).

Existen tres fuentes de cannabinoides:

- Los endocannabinoides producidos por los tejidos humanos (que fueron descubiertos en 1998). 
- Los fitocannabinoides que produce la cannabis y se conocen más de 120 fitocannabinoides diferentes.

- Los cannabinoides sintéticos que produce la industria farmacéutica.

Los efectos del cannabis medicinal dependen de diversos contrastes y proporciones de los fitocannabinoides. El sistema endocannabinoide humano fue descubierto en 1992. En este sistema existen los receptores CB1 y CB2 cuyo objetivo es la homeostasis del cuerpo, que es un estado de equilibrio que afecta procesos como el sueño, el dolor, el apetito, el humor, etc.

El sistema endocannabinoide tiene un papel muy importante en el sistema fisiológico de humanos y animales. Los endocannabinoides son también neuromoduladores que pueden afectar la transmisión de impulsos nerviosos, así como alteraciones del humor a través de la serotonina y dopamina.

\section{LA INDUSTRIA Y SUS RETOS}

A continuación, se reflexiona sobre las regulaciones recientes en México.

\section{Mercado Medicinal}

El mercado medicinal en México dependerá de importaciones en los primeros años en tres segmentos:

1. Cannabis grado farmacéutico.

2. Ingrediente activo de cannabis.

3. Cannabis producto terminado para uso medicinal, de bienestar OTC y suplementos.

Es probable que no se perciba aún, pero una de las grandes fortalezas de México es el potencial de la industria de la transformación que en su momento pudiera beneficiar la fabricación de productos terminados de cannabis muy por encima de otros países de Latinoamérica. Para ello es importante que la COFEPRIS pueda favorecer al mercado mexicano a través de nuevas formulaciones, propiedad intelectual e investigación clínica en población mexicana, ya que existe una desconexión entre científicos, médicos, agrónomos e instituciones de educación (Israel, EUA y Canadá son los más avanzados).

La prohibición ha creado una carencia de expertos en todas las áreas. De igual manera es necesario capacitar a médicos y pacientes. La terapia con cannabis se realiza de manera personalizada por lo que es diferente para cada persona. No se han encontrado dosis exactas para ciertas enfermedades, y en este mundo del cannabis conviven dos puntos de vista, el anecdótico y el científico. Un ejemplo de ello es que, hasta este momento, el CBD permanece en una zona "gris", el de la prescripción sin receta tanto en las farmacias o en todo tipo de tiendas. Finalmente, considero muy importante comunicar y educar sobre el cannabis medicinal ya que el mercado mexicano no tiene datos de unidades y valores lo que 
ha provocado un sobre precio en la venta actual y muy poca información en las etiquetas sobre concentraciones y usos, que seguramente en muchos casos engañan al consumidor. La falta de estos lineamientos ha generado un incremento de venta de productos en un mercado "gris" con poca presencia en farmacias y laboratorios nacionales lo que deriva en una falta de acceso de estas sustancias a miles de pacientes que requieren productos medicinales de alta calidad.

\section{Mercado recreativo}

La reciente decisión de la SCJN de derogar cinco artículos de la Ley General de Salud deja exactamente las cosas iguales y muy similares al mercado medicinal, ya que al no existir una industria legal con cadena producción, cadena de suministro y venta comercial, los únicos beneficiarios son los grupos que siembran $\mathrm{y}$ trafican ilegalmente en todo el territorio nacional y algunos grupos de activistas consumidores de cannabis.

Considero importante impulsar un programa de micro cultivo que tiene que ser apoyado por los gobiernos federal y locales. Los estados de la República son clave en la siembra y también pueden apoyar a los laboratorios estatales o universidades para la investigación agronómica. En todo el modelo de siembra en pequeña o gran escala, se deben de implementar normas para testing y trazabilidad que ayudarán a eliminar poco a poco el mercado negro y que los consumidores se sientan seguros de transitar de un mercado legal.

La regulación mexicana también debe ser un balance entre regulación, promoción y desarrollo de la industria, para alcanzar mercados internacionales y estándares de calidad nacionales, como el Good Manufacturing Practices y Good Agricultural Collective Practices.

Ante la gran especulación que se ha dado en el último año, es importante llevar a cabo estudios de la capacidad de siembra y de mercado recreativo, ya que a ciencia cierta nadie sabe la cantidad de consumidores actuales y potenciales que existen. Eso sería favorable para la definición del perfil de consumidores y lograr introducir al mercado diversas categorías de productos derivados de cáñamo y de cannabis con altos contenidos de THC e incluso nuevos cannabinoides como CBN y CBG. Por su parte, la SAGARPA a través de SNICS, deben de planear la genética, las zonas de siembra, los procesos de producción en los diferentes estados y finalmente hacer una política especial y diferenciada para el cáñamo y marihuana.

Finalmente enumero algunos de los retos que enfrentar la industria de cannabis mexicana:

1. Eficacia en la aplicación y tiempo de entrega de licencias.

2. Curva de aprendizaje de las autoridades sobre la regulación.

3. Definición clara de impuestos para las diversas categorías nacionales o importadas.

4. Integración de la cadena de suministro. 
5. Pruebas de calidad y etiquetado.

6. Consolidación de marcas y segmentos de mercado.

7. Educación, comunicación y eliminación de estigma.

8. Transparencia en todos los procesos de permisos y licencias.

9. Influencia de la delincuencia organizada en siembra y distribución.

10. Supervisión de la autoridad a colectivos para la que no vendan al público.

11. Acceso en tiendas de productos recreativos y farmacias a nivel nacional.

12. Falta de expertos en muchas áreas desde la siembra hasta la venta.

Esta obra está bajo licencia internacional Creative Commons ReconocimientoNo-Comercial-CompartirIgual 4.0.

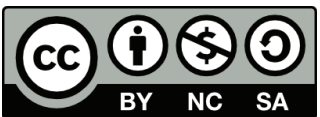

